\title{
Could the Sasang constitution itself be a risk factor of abdominal obesity?
}

\author{
Eunsu Jang, Younghwa Baek, Kihyun Park and Siwoo Lee*
}

\begin{abstract}
Background: Abdominal obesity $(\mathrm{AO})$ is a medical condition in which excess body fat accumulates in the abdomen. It may cause adverse effects on health and result in reduced life expectancy or increased health problems. While various genetic approaches have explained the risks of AO in Western society, the Sasang constitution (SC) has been identified as a risk factor in Korean medicine. Different SC types are associated with different fat distribution, body shapes and susceptibility to diseases. We evaluated whether the SC type could be a risk for $\mathrm{AO}$ in a cross-sectional study among Koreans.

Methods: In total, 2,528 subjects aged over 30 years were recruited from 23 medical clinics. We collected waist circumference (WC), weight, height, and some clinical information for AO from the subjects. A Chi-square test and a one-way ANOVA were performed according to SC type $(p<.05)$, while multiple logistic regression was used to produce odds ratios (ORs).

Results: The rates of AO in Tae-eumin (TE), Soeumin (SE), and Soyangin (SY) types were 63.7\%, 14.7\%, and 32.8\% in males and $84.8 \%, 41.7 \%$, and $52.8 \%$ in females, respectively. The TE type was associated with increased AO prevalence compared with the SE and SY types in males (OR 1.79; 95\% Cl 1.02-3.15, $\mathrm{p}=0.044$ and $\mathrm{OR} 1.74 ; 95 \% \mathrm{Cl}$ $1.18-2.58, p=0.006$, respectively) and females (OR 1.51; $95 \% \mathrm{Cl} 1.03-2.23, \mathrm{p}=0.037$ and $\mathrm{OR} 1.88 ; 95 \% \mathrm{Cl} 1.32-2.68$, $p<0.001$, respectively) after adjusting for age, BMI, hypertension, diabetes mellitus, hypertriglyceridemia, and low HDL cholesterol.
\end{abstract}

Conclusions: This study suggested that SC, particularly the TE type, might be significantly and independently associated with $\mathrm{AO}$ and could be considered a risk factor in predicting $\mathrm{AO}$.

Keywords: Abdominal obesity, Sasang constitutional medicine, Prevalence, Waist circumference, Risk factor

\section{Background}

Obesity is a medical condition in which excess body fat has accumulated to the extent that it may have an adverse effect on health, leading to reduced life expectancy and/or increased health problems [1]. Obesity, especially abdominal obesity (AO), is a substantial risk factor for hypertension, metabolic disease, cardiovascular disease, gallbladder disease, osteoarthritis, and sleep apnea [2].

Furthermore, the waist circumference (WC) plays pivotal roles in those diseases because of its central fat distribution [3-7]. Therefore, the World Health Organization (WHO) has classified obese guide

\footnotetext{
* Correspondence: bfree@kiom.re.kr

Division of Constitutional Medicine/Diagnosis Research Group, Korea Institute of Oriental Medicine, 1672 Yuseongdae-ro, Yuseong-gu, 305-811 Daejeon, Republic of Korea
}

according to not only body mass index (BMI) but also WC [8] and the National Cholesterol Education Program Adult Treatment Panel III also has defined AO as one of important factors for metabolic syndrome [9]. Eventually, the WHO has identified that human beings should overcome AO in the 21st century and observed that the wait for a cure may take a long time [10]. The fundamental cause of AO is presumed to be a combination of environmental factors (inappropriate eating and physical inactivity) and the organism's genes, such as the 5-HT2A gene and glucocorticoid receptor (GR) gene in Western society [11-15].

Sasang constitutional medicine (SCM) is a tailored Korean traditional medicine that classifies human beings into four constitutions: Taeyangin (TY), Soyangin (SY), Tae-eumin, (TE), and Soeumin (SE) [16]. Each 
constitution is classified by characteristics of body shape, face, voice, and psychological and physiological aspects $[17,18]$, and those characteristics are different from one constitution to another [19]. Therefore, each constitution has a different susceptibility to pathology and several chronic diseases. Hypertension and diabetes mellitus (DM) were revealed to be associated with a specific Sasang constitution (SC) [19-23].

According to SCM theory, lung hypo-function and liver hyper-function are related to a large $\mathrm{WC}$, and the TE type is associated with hyperactive liver function and a developed waist area $[16,17]$. We hypothesize that SC could be a risk for AO. Several family studies have been conducted to investigate the genetic evidence for SC, and they found that SC could be not only inherent but also a risk factor for obesity [24,25]. However, there has been no clinical study to show that SC could a risk factor for $\mathrm{AO}$.

In this study, we present indirect evidence of whether $\mathrm{SC}$ could be a risk factor for AO among Koreans.

\section{Methods}

This was a cross-sectional study conducted from Nov. 2007 to Jul. 2011 in 23 Korean medical clinics (KMCs).

\section{Study subjects and size}

The study size was assumed from a Bernoulli distribution. We calculated a sample size of at least 600 subjects of each constitution on the basis of a $95 \%$ confidence interval and a $4 \%$ margin of error. The eligible subjects were recruited from KMCs among individuals over 30 years old whose constitution had been confirmed by experts in SC. Individuals who could not understand and follow the researcher's indication or keep their measurement posture because of severe physical/mental illness were excluded. The detailed researcher's indication and the subjects' measurement posture were described in Jang's study [26]. The subjects with body deformation such as lump or congenital malformation in the measurement location, or pregnant women were also excluded. A total of 2,598 subjects (931 males and 1,667 females) were recruited from 23 KMCs. Three of them were excluded because of missing data. A total of 67 TY types were also excluded because of their low proportion in the Korean population. In total, 2,528 subjects (909 males and 1,619 females) were included in the final analysis. A flowchart of the study design is shown in Figure 1.

This study was approved by the Korea Institute of Oriental Medicine (KIOM) Institutional Review Board

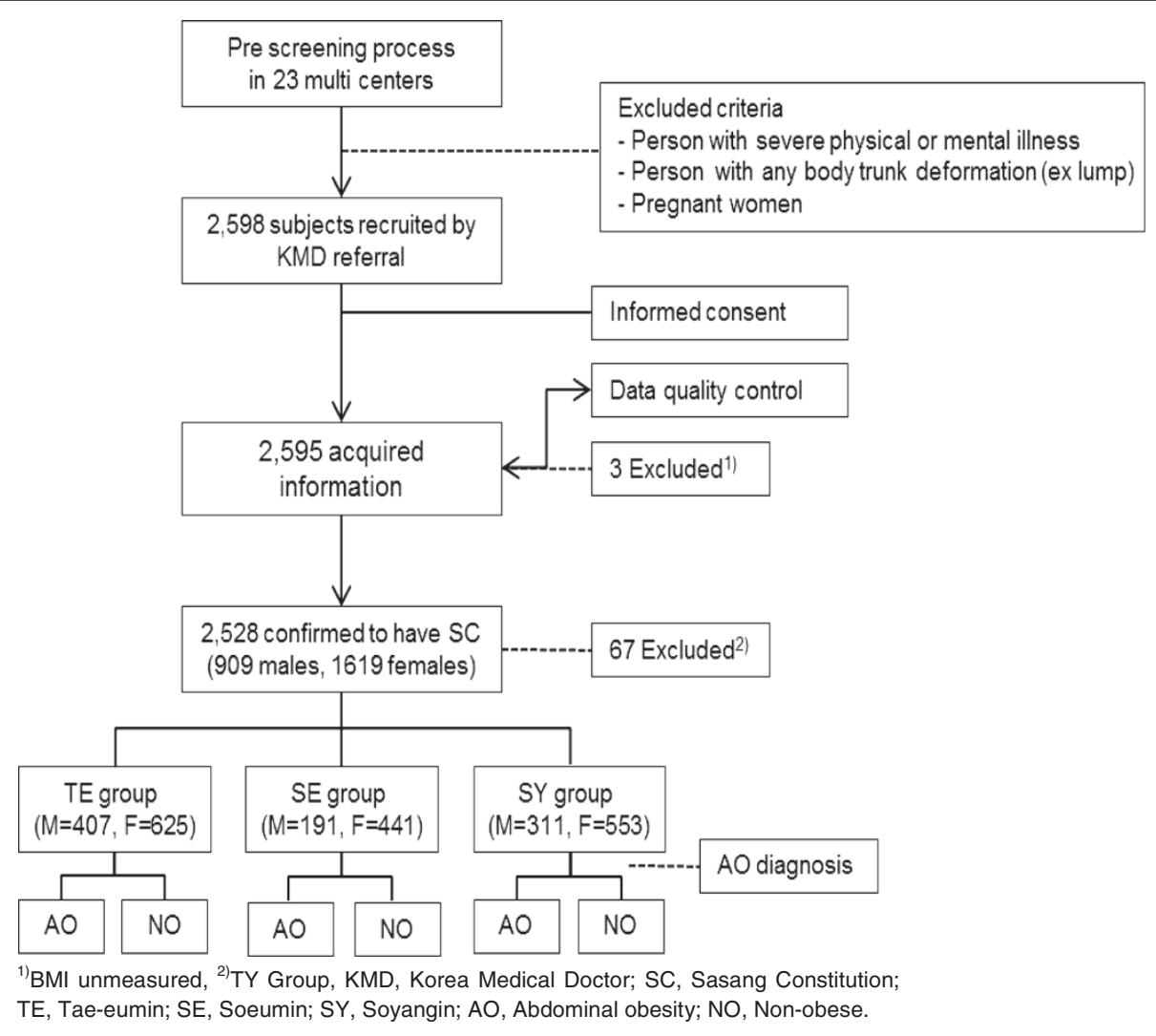

Figure 1 The flow chart of the study. 
(I-0910/02-001). Written informed consent for participation in this study was obtained from each of the subjects.

\section{Sasang constitutional diagnosis}

An SCM expert at each hospital diagnosed individual $\mathrm{SC}$ types. For accurate diagnoses, we strictly adhered to defined qualifications of the experts and subject criteria. The SCM experts had more than 5 years of experience in clinical practice. The administration of constitution-specific pharmaceuticals was used as an additional method to confirm the subject SC. A more detailed procedure of diagnosing SC was described in Song's study [27].

\section{Data collection}

We collected WC measurements to determine the AO prevalence according to SC. We also collected data on age, sex, body mass index (BMI), and blood pressure and blood samples to control for the influence of confounding factors, which are important risk factors for AO $[28,29]$. WC was measured around the level of the umbilical scar of the subjects, who took their upper clothing off and stood in an erect posture with their arms folded in front of their chest [26]. BMI was indirectly calculated through the weight and height, and the blood pressure was measured from each subject's left upper arm after enough rest. To reduce measurement bias among the KMCs, all instructors were educated by KIOM at least once per year, and KIOM monitored the progress of the data collection. All instructors followed a standard operation procedure (SOP) that was developed for the "Korea Constitution Multicenter Study" [26,30].

Blood samples were collected after more than 12 hours of fasting, and the fasting blood glucose, triglyceride (TG) and HDL cholesterol levels were tested by an authorized institution.

\section{Diagnostic criteria}

Hypertension was diagnosed by following the guidelines of the 7th Report of the JNC as $\geq 90 \mathrm{mmHg}$ for diastolic pressure, $\geq 140 \mathrm{mmHg}$ for systolic pressure or taking medicine for the treatment of high blood pressure [31]. DM was diagnosed with the ADA criteria as $\geq 126 \mathrm{mg} / \mathrm{dl}$ of fasting plasma glucose or taking medicine for the treatment of DM [32]. Hypertriglyceridemia was diagnosed as TG $\geq 150 \mathrm{mg} / \mathrm{dl}$, and low HDL cholesterol was diagnosed as HDL cholesterol $<40 \mathrm{mg} / \mathrm{dl}$ in males and $<50 \mathrm{mg} / \mathrm{dl}$ in females. To diagnose AO, we followed the WHO Report of Asia-Pacific guideline of $\mathrm{WC} \geq 90 \mathrm{~cm}$ for males and $\geq 80 \mathrm{~cm}$ for females [33].

Table 1 The Characteristics of subjects according to gender and constitution

\begin{tabular}{|c|c|c|c|c|}
\hline \multirow[t]{2}{*}{ Variables } & \multicolumn{3}{|c|}{ Constitution type } & \multirow[t]{2}{*}{$P$ value } \\
\hline & TE & SE & SY & \\
\hline \multicolumn{5}{|l|}{ Male } \\
\hline Number (\%) & $407(44.8)$ & $191(21)$ & $311(34.2)$ & \\
\hline Age (years) & $52.5 \pm 12.1^{b}$ & $48.5 \pm 12.2^{\mathrm{a}, \mathrm{b}}$ & $52.8 \pm 12.4^{\mathrm{a}}$ & $<0.001$ \\
\hline $\mathrm{BMI}\left(\mathrm{kg} / \mathrm{m}^{2}\right)$ & $25.8 \pm 2.8^{\mathrm{b}, \mathrm{c}}$ & $21.9 \pm 2.5^{\mathrm{a}, \mathrm{b}}$ & $23.7 \pm 2.6^{\mathrm{a}, \mathrm{c}}$ & $<0.001$ \\
\hline Systolic blood pressure $(\mathrm{mmHg})$ & $127.2 \pm 14.5^{\mathrm{b}, \mathrm{c}}$ & $120.4 \pm 14.6^{b}$ & $122.8 \pm 14.5^{c}$ & $<0.001$ \\
\hline Diastolic blood pressure $(\mathrm{mmHg})$ & $81.7 \pm 10.5^{b}$ & $77.4 \pm 11.3^{\mathrm{a}, \mathrm{b}}$ & $79.7 \pm 10.1^{c}$ & $<0.001$ \\
\hline Fasting blood glucose (mg/dl) & $105.6 \pm 31.2$ & $100.8 \pm 33.7$ & $105.8 \pm 33.6$ & 0.17 \\
\hline $\mathrm{TG}(\mathrm{mg} / \mathrm{dl})$ & $170.0 \pm 106.4^{\mathrm{b}}$ & $126.0 \pm 67.1^{\mathrm{a}, \mathrm{b}}$ & $158.3 \pm 106.0^{c}$ & $<0.001$ \\
\hline HDL cholesterol (mg/dl) & $39.1 \pm 9.6^{b, c}$ & $43.2 \pm 9.9^{b}$ & $41.8 \pm 11.1^{c}$ & $<0.001$ \\
\hline WC $(\mathrm{cm})$ & $92.4 \pm 7.4$ & $82.2 \pm 7.1$ & $86.5 \pm 7.9$ & $<0.001$ \\
\hline \multicolumn{5}{|l|}{ Female } \\
\hline Number (\%) & 625 & $441(27.2)$ & $553(34.2)$ & \\
\hline Age (years) & $53.6 \pm 12.7^{b, c}$ & $49.3 \pm 12.9^{b}$ & $50.19 \pm 12.1^{c}$ & $<0.001$ \\
\hline $\mathrm{BMI}\left(\mathrm{kg} / \mathrm{m}^{2}\right)$ & $25.5 \pm 3.0^{\mathrm{b}, \mathrm{c}}$ & $21.5 \pm 2.5^{\mathrm{a}, \mathrm{b}}$ & $22.8 \pm 2.6^{\mathrm{a}, \mathrm{c}}$ & $<0.001$ \\
\hline Systolic blood pressure $(\mathrm{mmHg})$ & $122.6 \pm 17.2^{\mathrm{b}, \mathrm{c}}$ & $116.2 \pm 16.0^{b}$ & $117.3 \pm 14.6^{c}$ & $<0.001$ \\
\hline Diastolic blood pressure $(\mathrm{mmHg})$ & $78.3 \pm 11.7^{b, c}$ & $74.2 \pm 11.3^{b}$ & $75.2 \pm 10.5^{c}$ & $<0.001$ \\
\hline Fasting blood glucose (mg/dl) & $101.7 \pm 315^{b}$ & $92.9 \pm 15.6^{a, b}$ & $98.0 \pm 32.1^{c}$ & $<0.001$ \\
\hline $\mathrm{TG}(\mathrm{mg} / \mathrm{dl})$ & $137.2 \pm 89.4^{\mathrm{b}, \mathrm{c}}$ & $100.8 \pm 57.7^{a, b}$ & $115.9 \pm 68.2^{\mathrm{a}, \mathrm{c}}$ & $<0.001$ \\
\hline HDL cholesterol (mg/dl) & $45.5 \pm 12.3^{b, c}$ & $51.0 \pm 12.6^{\mathrm{a}, \mathrm{b}}$ & $48.5 \pm 12.4^{a, c}$ & $<0.001$ \\
\hline$W C(\mathrm{~cm})$ & $88.9 \pm 8.8$ & $78.6 \pm 8.1$ & $81.2 \pm 8.2$ & $<0.001$ \\
\hline
\end{tabular}

Data shown are the mean \pm SD, unless otherwise indicated. ${ }^{a}$ Soeumin and Soyangin differ significantly, ${ }^{\mathrm{b}}$ Soeumin and Tae-eumin differ significantly, ${ }^{\mathrm{C}}$ Soyangin and Tae-eumin differ significantly. TE, Tae-eumin; SE, Soeumin; SY, Soyangin; BMI, Body mass index; TG, Triglycerides; WC, Waist circumference. 
Table 2 Prevalence of abdominal obesity stratified by gender and constitution

\begin{tabular}{|c|c|c|c|c|c|}
\hline \multirow[t]{2}{*}{ Variables } & \multicolumn{3}{|c|}{ Constitution type } & \multirow[t]{2}{*}{ Total } & \multirow[t]{2}{*}{$P$ value } \\
\hline & TE & SE & SY & & \\
\hline \multicolumn{6}{|l|}{ Male } \\
\hline $\mathrm{AO}$ & $259(63.7)$ & $28(14.7)$ & $102(32.8)$ & $389(42.8)$ & \\
\hline NO & $148(36.3)$ & $163(85.3)$ & $209(67.2)$ & $520(57.2)$ & $<0.001$ \\
\hline Total & $407(100)$ & $191(100)$ & $311(100)$ & $909(100)$ & \\
\hline \multicolumn{6}{|l|}{ Female } \\
\hline $\mathrm{AO}$ & $530(84.8)$ & $184(41.7)$ & $292(52.8)$ & $1006(62.1)$ & \\
\hline $\mathrm{NO}$ & 95 (15.2) & $257(58.3)$ & $261(47.2)$ & $613(37.9)$ & $<0.001$ \\
\hline Total & $625(100)$ & $441(100)$ & $553(100)$ & $1619(100)$ & \\
\hline
\end{tabular}

Data are shown as the $\mathrm{n}(\%)$. TE, Tae-eumin; $\mathrm{SE}$, Soeumin; SY, Soyangin; $\mathrm{AO}$, Abdominal obesity; NO, Non-obese.

\section{Statistical analysis}

Considering the influence of sexual differences, all analyses were separately conducted in males and females. A one-way ANOVA was used to compare continuous variables (Scheffé's post-hoc analysis). A Chi-square test was performed to compare the prevalence of AO according to SC. Multiple logistic regression was used to calculate odds ratios (ORs) for AO. To evaluate whether the SC could be a risk factor for AO, covariant variables, including age, BMI, hypertension, DM, hypertriglyceridemia, and low HDL cholesterol, were considered. We conducted all of the analyses using SPSS 17.0 software (SPSS Inc., Chicago, IL). The statistical levels of significance were considered to be $\mathrm{p}$ values $<0.05$.

\section{Results}

\section{General characteristics}

The distribution of SC into TE, SE, and SY types was $44.8 \%, 21 \%$, and $34.2 \%$ in males and $38.6 \%, 27.2 \%$, and $34.2 \%$ in females, respectively. The subjects' general characteristics, including age, body mass index, systolic blood pressure, diastolic blood pressure, fasting blood glucose, TG, HDL cholesterol, and WC, are shown in Table 1 according to gender and constitution.

\section{The rate of $\mathrm{AO}$ according to $\mathrm{SC}$}

The rate of $\mathrm{AO}$ was $42.8 \%$ in males and $62.1 \%$ in females. The prevalence of AO differed significantly according to constitution. The male AO rate according to constitution was $63.7 \%$ in the TE type, $14.7 \%$ in the SE type and $32.8 \%$ in the SY type, and the female AO rate according to constitution was $84.8 \%$ in the TE type, $41.7 \%$ in the SE type and $52.8 \%$ in the SY type. The details are shown in Table 2.

\section{ORs for AO before and after adjustment}

Table 3 shows a sequentially developed multiple logistic regression model of AO. Model 1 was crude, without adjustment, model 2 was adjusted for age and BMI, and model 3 was adjusted for age, BMI, hypertension, DM, hypertriglyceridemia, and low HDL cholesterol. Because the TE type was assumed to be a more dangerous risk factor than other types, the results were described as SE type versus TE type and SY type versus TE type.

The result revealed that the TE type was associated with increased AO prevalence compared with SE and SY types in males (model 1, OR 10.19; 95\% CI 6.5-15.96, $\mathrm{p}<0.001$ and OR 3.59; 95\% CI 2.63-4.9, p $<0.001$, respectively). The TE type remained significantly associated with increased AO prevalence after adjusting for age and BMI (model 2, OR 1.77; 95\% CI 1.01-3.16, p = 0.045 and OR 1.72 ; 95\% CI 1.17-2.53, $\mathrm{p}=0.006$, respectively) and age, BMI, hypertension, DM, hypertriglyceridemia, and low HDL cholesterol (model 3, OR 1.79; $95 \%$ CI $1.02-3.15, \mathrm{p}=0.044$ and OR 1.74 ; $95 \%$ CI $1.18-$ $2.58, \mathrm{p}=0.006$, respectively).

We also found a similar trend in females. The TE type was associated with increased AO prevalence compared with SE and SY types (model 1, OR 7.79; 95\% CI 5.84$10.4, \mathrm{p}<0.001$ and OR 4.99; 95\% CI 3.79-6.56, p < 0.001, respectively), and the TE type remained significantly associated with increased $\mathrm{AO}$ prevalence after adjusting for age and BMI (model 2, OR 1.65; 95\% CI 1.13-2.41, $\mathrm{p}=0.01$ and OR 1.9; 95\% CI 1.35-2.7, $\mathrm{p}<0.001$, respectively) and age, BMI, hypertension, DM,

Table 3 Adjusted odds ratios and $95 \% \mathrm{Cl}$ for abdominal obesity according to constitution

\begin{tabular}{|c|c|c|c|c|c|c|}
\hline \multirow[t]{2}{*}{ Variables } & \multicolumn{2}{|l|}{ Model 1} & \multicolumn{2}{|l|}{ Model 2} & \multicolumn{2}{|l|}{ Model 3} \\
\hline & OR $(95 \% \mathrm{CI})$ & $P$ value & OR $(95 \% \mathrm{Cl})$ & $P$ value & OR $(95 \% \mathrm{Cl})$ & $P$ value \\
\hline \multicolumn{7}{|l|}{ Male } \\
\hline SE Type:TE Type & $1: 10.19(6.5-15.96)$ & $<0.001$ & $1: 1.77(1.01-3.16)$ & 0.045 & $1: 1.79(1.02-3.15)$ & 0.044 \\
\hline SY Type:TE Type & $1: 3.59(2.63-4.9)$ & $<0.001$ & $1: 1.72(1.17-2.53)$ & 0.006 & $1: 1.74(1.18-2.58)$ & 0.006 \\
\hline \multicolumn{7}{|l|}{ Female } \\
\hline SE Type:TE Type & $1: 7.79(5.84-10.4)$ & $<0.001$ & $1: 1.65(1.13-2.41)$ & 0.01 & $1: 1.51(1.03-2.23)$ & 0.037 \\
\hline SY Type:TE Type & $1: 4.99(3.79-6.56)$ & $<0.001$ & $1: 1.9(1.35-2.7)$ & $<0.001$ & $1: 1.88(1.32-2.68)$ & $<0.001$ \\
\hline
\end{tabular}

Results from logistic regression analysis, Model 1- crude. Model 2- adjusted for age and BMI. Model 3- adjusted for age, BMI, hypertension, DM, hypertriglyceridemia, and low HDL cholesterol. TE, Tae-eumin; SE, Soeumin; SY, Soyangin; OR, odds ratio; Cl, confidence interval. 
hypertriglyceridemia, and low HDL cholesterol (model 3, OR 1.51; 95\% CI 1.03-2.23, $\mathrm{p}=0.037$ and OR 1.88; 95\% CI $1.32-2.68, \mathrm{p}<0.001$, respectively).

\section{Discussion}

Several studies have suggested that the SC could be associated with some chronic diseases, and it has been recognized as an independent risk factor [19-23]. Recently, a gene-level study also revealed that $\mathrm{SC}$ was associated with $\mathrm{AO}$ [34]. In this cross-sectional study, we aimed to determine whether the $\mathrm{SC}$ could be a risk factor for $\mathrm{AO}$ among Koreans.

This study suggested that SC may be a significant and independent risk factor of AO. Specifically, the TE type was associated with increased AO prevalence compared with the SE and SY types in males (OR 1.79; 95\% CI 1.02-3.15, and OR 1.74; 95\% CI 1.18-2.58, respectively) and females (OR 1.51; 95\% CI 1.03-2.23, and OR 1.88; 95\% CI 1.32-2.68, respectively), even after adjusting for age, BMI, hypertension, DM, hypertriglyceridemia, and low HDL cholesterol. This result means that the TE type could be more susceptible to AO than other types, which is similar to the trend found for hypertension, $\mathrm{DM}$, and metabolic syndrome, which are associated with $\mathrm{SC}$ [19-23].

The results revealed that the WC was different according to SC type, and the TE type had the largest WC, which was similar to other characteristics. The rates of $\mathrm{AO}$ were different among SC types, and the rate of $\mathrm{AO}$ in the TE type was higher than in other types in both genders. However, because the comparatively larger WC of the TE type may be caused by a relatively higher BMI, age, and several chronic diseases [35], it is necessary to explain the pure influence of SC itself. Accordingly, we calculated ORs for $\mathrm{AO}$ with a logistic regression analysis model after adjusting for the influence of potential variables. The multiple logistic regression analysis showed that large differences in the OR between the TE type and other types prior to adjusting for the potential variables (model 1) were still significant in models 2 and 3. Furthermore, this trend was similar in both males and females.

This trend supports the hypothesis that people classified as TE type might have a bigger belly and a higher prevalence rate for $\mathrm{AO}$ compared with other types, even if each type has similar physical characteristics. This finding might also be indirect evidence for SCM, which suggests that body shape could develop differently from one constitution to another.

In this study, we tried to enroll a representative Korean population from nationwide centers. We also minimized measurement error by following SOPs [30] and blood testing error by utilizing a qualified institution.
The prevalence rates of $\mathrm{AO}$ in this study were relatively high compared with a previous study conducted by the Korean government [36]. For this reason, we assumed that the average age in this study was relatively higher.

Our study has several limitations. Previously, a large Korean family study suggested a significant association of chromosomes 8q11.22-23 and 11q22.1-3 with SC [25], and another study found that SC was associated with $\mathrm{AO}$ at the genetic level [34]. Family surveys and gene-level studies could be a good method to demonstrate whether $\mathrm{SC}$ is an inherent risk factor for $\mathrm{AO}$. However, because our study had a cross-sectional design, we could not analyze the association between inherent $\mathrm{SC}$ and AO. In addition, we did not control for environmental factors, such as meals, lifestyle, and exercise habits, which are acquired risk factors for AO.

We believe that further studies on not only a direct comparison between constitutions considering acquired environmental factors for $\mathrm{AO}$ but also on inherent family SC are needed.

\section{Conclusions}

This study suggested that SC, especially the TE type, might be significantly and independently associated with AO. This finding reveals that SC should be considered a risk factor in predicting $\mathrm{AO}$.

\section{Abbreviations \\ TE: Tae-eumin; SE: Soeumin; SY: Soyangin; AO: Abdominal obesity; NO: Non-obese; WC: Waist circumference.}

\section{Competing interests}

The authors declare that they have no competing interests.

\section{Authors' contributions}

EJ carried out the qualitative data analysis and drafted the manuscript. YB coordinated the study, participated in data collection, and contributed to the interpretation of data and content of this manuscript. SL conceived of this study, was the Principal Investigator, participated in its design and coordination, and contributed to the interpretation of data and content of this manuscript. KP also participated in the qualitative data analysis. All of the authors critically contributed to the final manuscript and approved the final version.

\section{Acknowledgments}

This research was supported by the National R\&D Program through the National Research Foundation of Korea (NRF) funded by the Ministry of Education, Science and Technology (No. 2006-2005175) and Korea Institution of Oriental Medicine (KIOM) grant funded by the Korean government (MEST) (No. K13070).

Received: 11 July 2012 Accepted: 8 February 2013

Published: 2 April 2013

\section{References}

1. Haslam DW, James WP: Obesity. Lance 2005, 366(9492):1197-1209.

2. Sim KW, Lee SH, Lee HS: The relationship between body mass index and morbidity in Korea. Korean J Obesity 2001, 10(2):147-155.

3. Kannel WB, Adrienne Cupples L, Ramaswami R, Stokes J, Kreger BE, Higgins M: Regional obesity and risk of cardiovascular disease; the Framingham Study. J Clin Epidemiol 1991, 44(2):183-190. 
4. Bouchard C, Bray GA, Hubbard VS: Basic and clinical aspects of regional fat distribution. Am J Clin Nutr 1990, 52(5):946.

5. Prineas RJ, Folsom AR, Kaye SA: Central adiposity and increased risk of coronary artery disease mortality in older women. Ann Epidemiol 1993 3(1):35-41.

6. Detection EPO: Evaluation, and treatment of high blood cholesterol in adults. Executive summary of the third report of The National Cholesterol Education Program (NCEP) Expert panel on detection, evaluation, and treatment of high blood cholesterol in adults (Adult Treatment Panel III). JAMA 2001, 285(19):2486-2497.

7. Fujimoto WY, Bergstrom RW, Boyko EJ, Leonetti DL, Newell--Morris LL, Wahl PW: Susceptibility to development of central adiposity among populations. Obes Res 2012, 3(Suppl 2):179-186.

8. WHO: Obesity: preventing and managing the global epidemic. World Health Organization technical report series no. 894. Geneva; Switzerland: World Health Organization; 2000.

9. Grundy SM, Cleeman JI, Daniels SR, Donato KA, Eckel RH, Franklin BA, Gordon DJ, Krauss RM, Savage PJ, Smith SC Jr: Diagnosis and management of the metabolic syndrome. Circulation 2005, 112(17):2735-2752.

10. WHO: 2008-2013 action plan for the global strategy for the prevention and control of noncommunicable diseases. Geneva; Switzerland: World Health Organization; 2008:42.

11. Elliott SS, Keim NL, Stern JS, Teff K, Havel PJ: Fructose, weight gain, and the insulin resistance syndrome. Am J Clin Nutr 2002, 76(5):911-922.

12. Perez-Pozo S, Schold J, Nakagawa T, Sanchez-Lozada L, Johnson R, Lillo JL: Excessive fructose intake induces the features of metabolic syndrome in healthy adult men: role of uric acid in the hypertensive response. Int J Obes 2009, 34(3):454-461.

13. Choi ME: The not-so-sweet side of fructose. J Am Soc Nephrol 2009, 20(3):457-459.

14. Rosmond R, Bouchard C, Björntorp P: 5-HT2A receptor gene promoter polymorphism in relation to abdominal obesity and cortisol. Obes Res 2012, 10(7):585-589.

15. Rosmond R, Chagnon YC, Holm G, Chagnon M, Pérusse L, Lindell K, Carlsson B, Bouchard C, Björntorp P: A glucocorticoid receptor gene marker is associated with abdominal obesity, leptin, and dysregulation of the hypothalamic-pituitary-adrenal axis. Obes Res 2012, 8(3):211-218.

16. Lee JM: Longevity and life preservation in oriental medicine (東醫壽世保元). Seoul, Korea: Kyung Hee Univ. Press; 1996.

17. Kim JY, Pham DD: Sasang constitutional medicine as a holistic tailored medicine. Evid-Based Complementary Altern Med 2009, 6(Suppl 1):11-19.

18. Shim EB, Lee S, Kim JY, Earm YE: Physiome and sasang constitutional medicine. J Physio/ Sci 2008, 58(7):433-440.

19. Lee $T$, Lee $S$, Choe B, Song I: A study on the prevalences of chronic diseases according to Sasang constitution at a health examination center. J Sasang Constitut Med 2005, 17(2):32-45.

20. Lee TG, Koh B, Lee $S$ : Sasang constitution as a risk factor for diabetes mellitus: a cross-sectional study. Evid-Based Complementary Altern Med 2009, 6(1):99-103.

21. Lee J, Lee E, Yoo J, Kim Y, Koh B: The sasang constitutional types can act as a risk factor for hypertension. Clin Exp Hypertens 2011, 33(8):525-532.

22. Choi K, Lee J, Yoo J, Lee E, Koh B: Sasang constitutional types can act as a risk factor for insulin resistance. Diabetes Res Clin Pract 2011 91(3):e57-e60.

23. Song KH, YU SG, Kim JY: Prevalence of metabolic syndrome according to Sasang constitutional medicine in Korean subjects. Evid-Based Complementary Altern Med 2012, 2012:646794.

24. Lee MK, Jang ES, Sohn HY, Park JY, Koh BH, Sung J, Kim Jl, Kim JY, Seo JS: Investigation of genetic evidence for Sasang constitution types in South Korea. Genomics \& Informatics 2009, 7(2):107-110.

25. Won HH, Lee S, Jang E, Kim KK, Park YK, Kim YJ, Kim YS, Kim BY, Kim JY, Kim JW: A genome-wide scan for the sasang constitution in a korean family suggests significant linkage at chromosomes 8q11. 22-23 and 11q22. 1-3. J Altern Complement Med 2009, 15(7):765-769.

26. Jang $E$, Kim JY, Lee $H$, Kim H, Baek Y, Lee S: A Study on the reliability of Sasang constitutional body trunk measurement. Evid-Based Complementary Altern Med 2011, 2012:604842.

27. Song KH, Yu SG, Cha S, Kim JY: Association of the apolipoprotein A5 gene $-1131 \mathrm{~T}>\mathrm{C}$ polymorphism with serum lipids in Korean subjects: impact of Sasang constitution. Evid-Based Complementary Altern Med 2011, 2012:598394.

28. Després JP, Lemieux I: Abdominal obesity and metabolic syndrome. Nature 2006, 444(7121):881-887.

29. Sánchez-Castillo CP, Velásquez-Monroy O, Lara-Esqueda A, Berber A, Sepulveda J, Tapia-Conyer R, T James WP: Diabetes and hypertension increases in a society with abdominal obesity: results of the Mexican National Health Survey 2000. Public Health Nutr 2005, 8(01):53-60.

30. KIOM: Development of Diagnostic and Herbal Drug System based on Traditional Constitutional Korean Medicine. Daejeon; Korea: Korea Institute of Oriental Medicine; 2007

31. Chobanian AV, Bakris GL, Black HR, Cushman WC, Green LA, Izzo JL Jr, Jones DW, Materson BJ, Oparil S, Wright JT Jr: Seventh report of the joint national committee on prevention, detection, evaluation, and treatment of high blood pressure. Hypertension 2003, 42(6):1206-1252.

32. Association AD: Diagnosis and classification of diabetes mellitus. Diabetes Care 2010, 33(Suppl 1):62-69.

33. WHO: The Asia-Pacific perspective: redefining obesity and its treatment. Geneva; Switzerland: World Health Organization; 2000.

34. Cha S, Koo I, Park BL, Jeong S, Choi SM, Kim KS, Shin HD, Kim JY: Genetic Effects of FTO and MC4R Polymorphisms on Body Mass in Constitutional Types. Evid-Based Complementary Altern Med 2011, 2011. doi:10.1093/ecam/ nep1162.

35. Kim JW, Jeon SH, Sull YK, Kim KK, Lee EJ: A study on the body shape classified by Sasang constitutions and gender using physical measurements. J Sasang Constitut Med 2006, 18(1):54-61.

36. KCDC: The Third Korea National Health and Nutrition Examination Survey (KNHANES III) 2005 Health Examination. Gwacheon; Korea: Korea Centers for Disease Control and Prevention; 2006.

doi:10.1186/1472-6882-13-72

Cite this article as: Jang et al:: Could the Sasang constitution itself be a risk factor of abdominal obesity?. BMC Complementary and Alternative Medicine 2013 13:72.

\section{Submit your next manuscript to BioMed Central and take full advantage of:}

- Convenient online submission

- Thorough peer review

- No space constraints or color figure charges

- Immediate publication on acceptance

- Inclusion in PubMed, CAS, Scopus and Google Scholar

- Research which is freely available for redistribution

Submit your manuscript at www.biomedcentral.com/submit
C BioMed Central 